\title{
Better together? How intergroup associations affect energy balance and feeding behavior in wild bonobos
}

\author{
Stefano Lucchesi ${ }^{1,2}$ (D) $\cdot$ Leveda Cheng ${ }^{1,2} \cdot$ Tobias Deschner $^{1}$ (D) $\cdot$ Roger Mundry $^{1} \cdot$ Erin G. Wessling ${ }^{2}$ (D) \\ Martin Surbeck ${ }^{1,2}$ (1)
}

Received: 19 May 2020 / Revised: 26 November 2020 / Accepted: 30 November 2020 / Published online: 10 December 2020

(C) The Author(s) 2020

\begin{abstract}
When the benefits of interacting with out-group members exceed the associated costs, social groups may be expected to be tolerant towards each other. However, in many species exhibiting intergroup tolerance, the nature of benefits gained from intergroup encounters remains unclear. We investigated the potential costs and benefits associated with intergroup associations in bonobos, a species with varying degrees of intergroup tolerance, by testing whether these associations conferred energetic benefits to participants under different socioecological contexts and whether the consequences of these associations substantially differed from within-group competition. We used measures of socioecological factors (fruit abundance and group size), feeding and ranging behaviors, and a physiological marker of energy balance (urinary c-peptide of insulin) collected over a 19-month period from two neighboring wild communities in the Kokolopori Bonobo Reserve, Democratic Republic of the Congo. We found that intergroup associations were not related to individuals' energy balance, but they were related to variations in individuals' ranging and feeding behavior. Specifically, bonobos traveled longer distances, visited larger fruit patches, and increased the time spent feeding on fruits on days they associated with the neighboring group. These adaptations in feeding behavior may be strategies to offset the energetic costs of increased travel distances. In the absence of obvious energetic benefits and with clear strategies employed to offset energetic costs, it is likely that intergroup associations in bonobos provide benefits unrelated to energy acquisition, such as social benefits. Our study sheds light on the potential incentives promoting social networks to extend beyond and across groups in a tolerant species.
\end{abstract}

\section{Significance statement}

Intergroup encounters can be energetically costly due to increased competition over resources. Yet, some species associate with out-group individuals for extended periods of time when the benefits of participating in these associations exceed the potential costs. Bonobos, a species exhibiting intergroup tolerance, modified their feeding behavior during intergroup associations by feeding on larger fruit patches and increasing their time spent feeding on fruits, likely to offset energetic costs of increased travel distances. As results, individuals' energy balance was not related with intergroup associations. The employment of such strategies in addition to the absence of clear energetic benefits suggests that intergroup associations in bonobos provide social rather than ecological benefits.

Keywords C-peptide $\cdot$ UCP $\cdot$ Tolerance $\cdot$ Ecological costs $\cdot$ Social benefits $\cdot$ Intercommunity encounters

Communicated by K. Langergraber

Stefano Lucchesi

steluc86@hotmail.it

1 Max Planck Institute for Evolutionary Anthropology, Deutscher Platz 6, 04103 Leipzig, Germany

2 Department of Human Evolutionary Biology, Harvard University, 11 Divinity Ave, Cambridge, MA 02138, USA

\section{Introduction}

Reactions to out-group members in group-living species range from agonistic (humpback whales, Megaptera novaeangliae: Clapham et al. 1992; spotted hyenas, Crocuta crocuta: Boydston et al. 2001; non-human primates: Brown 2013; banded mongooses, Mungos mungo: Thompson et al. 2017) to tolerant (killer whales, Orcinus orca: Bisther 2002; spotted hyenas, C. crocuta: Smith et al. 2008) and even affiliative 
(polydomous ants, Iridomyrmex purpureus: Robinson and Barker 2017; humans and great apes: Pisor and Surbeck 2019), with some species such as humans spanning the full range of potential reactions (Kelly 2005; Fry 2012). The nature of these interactions is influenced by a variety of socioecological factors including the availability, distribution, and location of feeding resources (spotted hyenas, C. crocuta: Boydston et al. 2001; coal tits, Parus ater: Brotons and Herrando 2003; non-human primates review: Koenig 2002; Brown 2013; banded mongooses, M. mungo: Furrer et al. 2011; Verreaux's sifakas, Propithecus verreauxi: Koch et al. 2016; polydomous ants, I. purpureus; and humans: Robinson and Barker 2017) and mating opportunities (humpback whales, Megaptera novaeangliae: Clapham et al. 1992; chacma baboons, Papio cynocephalus ursinus: Kitchen et al. 2004), as well as the relative sizes of the interacting groups (wood ants, Formica xerophila: Tanner 2006; lions, Panthera leo: Mosser and Packer 2009). Generally, when resources are economically defensible and the benefits of exclusive resource access surpass the costs of resource defense, groups are expected to interact agonistically (Grant 1993; Maher and Lott 2000; Dubois and Giraldeau 2003). Conversely, when resources are not economically defensible due to their abundance or dispersion, or when the costs of sharing resources with neighbors are offset by the benefits conferred by these interactions, groups may show tolerance to out-group members (Dubois and Giraldeau 2003; Robinson and Barker 2017), to the extent that distinct social units may choose to participate in prolonged intergroup associations (plains zebras, Equus burchelli: Rubenstein and Hack 2004; African elephants, Loxodonta africana: Wittemyer et al. 2005; sperm whales, Physeter macrocephalus: Whitehead et al. 2012; bonobos, Pan paniscus: Sakamaki et al. 2018; Lucchesi et al. 2020).

Agonistic intergroup interactions generally incur costs to the participating individuals in the form of physical injuries (chimpanzees, Pan troglodytes: Amsler 2009; African wild dogs, Lycaon pictus: Jordan et al. 2017), longer travel distances in order to avoid or search for out-group members (white-faced capuchin monkeys, Cebus capucinus: Crofoot 2013; lions, P. leo: Yiu et al. 2015; mountain gorillas, Gorilla beringei beringei: Seiler et al. 2018), and/or limitation of individuals' ranging patterns and consequent access restriction to resources where home ranges overlap (wolves, Canis lupus: Mech and Harper 2002; chimpanzees, P. troglodytes: Herbinger et al. 2001; Wrangham et al. 2007; yellow baboons, Papio cynocephalus: Markham et al. 2012; coyotes, Canis latrans: Gese 2001; humans: Kelly 2005). The consequences of tolerant intergroup interactions are also variable. Even when intergroup encounters are tolerant, interactions with outgroups can still carry costs to participants similar to those caused by an increase in group size. Such costs generally originate from higher competition over food resources due to a larger number of co-feeding individuals (Chapman and
Valenta 2015; Markham et al. 2015), which may result in increased travel distances to find sufficient food (chimpanzees, Pan troglodytes and spider monkeys, Ateles geoffroyi: Chapman et al. 1995; red colobus monkeys, Procolobus badius: Gillespie and Chapman 2001), increased time individuals allocate to feeding (yellow baboons, P. cynocephalus: Muruthi et al. 1991; black-and-white colobus, Colobus polykomos: Dasilva 1992), and higher number and/or size of feeding patches visited (howler monkeys, Alouatta palliata: Leighton and Leighton 1982; white-throated sparrows, Zonotrichia albicollis: Pearson 1989; muriquis, Brachyteles arachnoides: Strier 1989).

Conversely, intergroup tolerance can also offer energetic benefits to individuals in a number of ways. These benefits may include the possibility to buffer periods of local resource shortage by accessing resources in neighboring home ranges (polydomous ants, Formica lugubris: Ellis et al. 2014; humans and great apes: Jaeggi et al. 2016; Pisor and Surbeck 2019; humans: Robinson and Barker 2017), or by improving food access in unfamiliar areas via information exchange (non-human primates: Isbell and Vuren 1996; hooded crows, Corvus corone cornix: Sonerud et al. 2001; shorttailed fruit bats, Carollia perspicillata: Ratcliffe and Hofstede 2005). Non-energetic benefits include providing additional mating opportunities (Hanuman langurs, Semnopithecus entellus: Launhardt et al. 2001; Verreaux's sifaka, P. verreauxi: Lawler 2007) and social partners (African elephants, L. africana: Wittemyer et al. 2005; bonobos, P. paniscus: Sakamaki et al. 2018), protection from predation (African elephants, L. africana: Wittemyer et al. 2005; proboscis monkeys, Nasalis larvatus: Matsuda et al. 2010), and the possibility to transfer to new social groups (bonobos, P. paniscus: Hohmann 2001, Sakamaki et al. 2015; meerkats, Suricata suricatta: Drewe et al. 2009). The relative importance of these costs and benefits to individuals directly impacts the way group members interact with out-groups during intergroup encounters. For instance, group members may bear the energetic costs of shared access to food resources when they can gain benefits of extra-group mating opportunities (humans and non-human primates: Pisor and Surbeck 2019) or alloparental care (African elephants, L. africana: Wittemyer et al. 2005). Balancing these costs and benefits is especially relevant in the context of multilevel societies, where social tiers cluster in higher order social units nested within each other (plain zebras, E. burchelli: Rubenstein and Hack 2004; African elephants, L. africana: Wittemyer et al. 2005; geladas, Theropithecus gelada: Snyder-Mackler et al. 2012; mammal review: Grueter et al. 2012).

As a species exhibiting intergroup tolerance with encounters frequently developing into long-lasting intergroup associations extending over several consecutive days (Idani 1990; Sakamaki et al. 2018; Furuichi 2020; Lucchesi et al. 2020), bonobos (P. paniscus) are an excellent model in which to 
investigate the relative benefits and costs of intergroup associations. Bonobos are hominoid primates that live in multimale, multi-female social groups referred to as communities, which regularly fission into smaller parties to adapt to temporal fluctuations in food availability (Mulavwa et al. 2008; Surbeck et al. 2015). Their diet is primarily frugivorous, although terrestrial herbaceous vegetation (THV) is consumed in significant proportions all year round (Hohmann et al. 2006; Inogwabini and Matungila 2009). Reduced feeding competition due to the high productivity of bonobos' habitats is believed to promote tolerance both within and between communities (White 1998; Hohmann et al. 2006; Mulavwa et al. 2008; Furuichi 2011). However, recent findings suggest that habitat productivity is likely a limiting factor influential to the degree of tolerance individuals and communities exhibit (Nurmi et al. 2018; Sakamaki et al. 2018; Furuichi 2020; Lucchesi et al. 2020; LC et al. unpubl. data), and some suggest that the productivity of bonobo habitats may be similar to that of some chimpanzee populations (Furuichi 2020).

We have recently demonstrated that relatively high fruit abundance facilitates the occurrence of intercommunity encounters and that when the number of maximally tumescent females in a party is high and communities range in less familiar areas of their home range, encounters are likely to develop into prolonged intercommunity associations (Lucchesi et al. 2020). While examining the socioecological context under which encounters occur and terminate offers valuable insights into the potential benefits and costs these events confer to the participating individuals, the trade-off between benefits and costs of intercommunity associations (hereafter "associations"), and the way individuals maximize the net benefits of these associations, remain unclear.

Building on our previous findings, the potential benefits of associating with extra-community individuals may be related to both ecological and social factors. On the ecological level, benefits may come in the form of improved foraging efficiency in less familiar areas due to potential information exchange (cliff swallows, Hirundo pyrrhonota: Brown 1988; glossy black-cockatoos, Calyptorhynchus lathami: Cameron 2006; mouse-tailed bats, Rhinopoma microphyllum: Cvikel et al. 2015), or by following foraging routes of extra-community members more familiar with food location in such areas (humans: Cashdan et al. 1983; hooded crows, C. corone cornix: Sonerud et al. 2001; short-tailed fruit bats, Carollia perspicillata: Ratcliffe and Hofstede 2005). This hypothesis is supported by our previous finding that bonobos were less likely to terminate associations when ranging in less familiar areas of their home range (Lucchesi et al. 2020). On the social level, the fact that communities were less likely to terminate associations when the number of maximally tumescent females in the party was high indicates the possibility of reproductive advantages to these associations (but see Ishizuka et al. 2018, 2020).
One avenue to discern the kind of benefits associations provide, and specifically if these benefits are related to ecology, is to analyze associations participants' energy balance, which is the direct result of energy intake from food minus energy expenditure from activity and physiological processes (Emery Thompson 2017). Energy balance can thus inform us whether associations confer benefits related to improved access to food (energetic benefits hypothesis) and to evaluate the plausibility of alternative benefits (e.g., social and mating benefits) in case they do not (non-energetic benefits hypothesis).

In line with the energetic benefits hypothesis, if associations are a strategy to improve food access, we would expect the energy balance of individuals to increase during associations. Moreover, if ranging with extra-community members allows more efficient discovery of food patches in less familiar areas, we would anticipate the energetic status of individuals to be higher in these areas during associations. Conversely, according to the non-energetic benefits hypothesis, individuals may bear potential energetic costs of associations if they obtain associated benefits in domains not related to foraging efficiency (e.g., social benefits). Energetic costs may derive from increased travel distances (Chapman and Valenta 2015; Markham et al. 2015) or a decrease in time spent foraging as time is allocated to social interactions instead (Lehmann et al. 2007). However, community members may adapt their behavior to offset these costs as much as possible. For instance, individuals may change their feeding behavior in response to associations, e.g., by targeting high energy food such as fruits (black-and-white colobus, C. polykomos: Dasilva 1992; bonobos, P. paniscus: Hohmann et al. 2006; Serckx et al. 2015) or by selecting larger feeding patches that could accommodate a higher number of co-feeders (howler monkeys, Alouatta palliata: Leighton and Leighton 1982; white-throated sparrows, Z. albicollis: Pearson 1989; muriquis, B. arachnoides: Strier 1989). In this case, individuals' energy balance would not decrease during associations, but we would expect to observe behavioral adaptations to offset the energetic costs.

To differentiate between the energetic benefits and the nonenergetic benefits hypotheses, we quantified the relationship between associations and the energetic status of individuals measured as levels of urinary c-peptide of insulin (UCP). UCPs are a valuable index of individuals' energy balance, indicative of both diet quality (Deschner et al. 2008; Grueter et al. 2014) and food availability (Sherry and Ellison 2007; Emery Thompson and Knott 2008; Georgiev 2012; Wessling et al. 2018), as well as changes in body mass (Deschner et al. 2008; Girard-Buttoz et al. 2011) and in physiological conditions (Emery Thompson et al. 2012). UCPs have been shown to track short-term variation in energy balance both in humans and in non-human primates. In humans, UCP levels increased both during the course of the day and following meals (Cousin 1980, Meystas 1981). Similarly, UCP levels increased as the day progressed in mountain gorillas, likely reflecting food 
intake, and UCP levels were related with diurnal variation in hourly fruit intake in chimpanzees (Georgiev 2012). We thus predict that, in bonobos, individuals' UCP levels will increase when the abundance of fruit resources is higher, which can serve as a biological validation of this index. Importantly, as stated above, individuals' energy balance may not be related to associations because of the strategies bonobos might employ to mitigate potential energetic costs. Therefore, we also investigated the relationship between associations and bonobo feeding behavior by examining whether the number and the size of the visited fruit patches and the time spent feeding on fruits (high energy food) and on THV (low energy food) varied in relation to associations. If individuals adapt their behavior to offset potential energetic costs, we expect them to visit more and/or larger feeding patches and to increase their time spent feeding on fruits during associations. However, since the aforementioned patterns may also reflect benefits of associations (e.g., individuals may feed from larger feeding patches by following extra-community members in unfamiliar areas), to provide evidence for the non-energetic benefits hypothesis, these patterns should be observed in concomitance with a decrease in energy balance during associations.

\section{Methods}

\section{Field site and study subjects}

We collected data on two neighboring communities of wild bonobos from July 2016 to February 2018 in the Kokolopori Bonobo Reserve, central Democratic Republic of the Congo (DRC) (Surbeck et al. 2017). During the study period, the smaller community Ekalakala consisted of 13 individuals including three adult males ( $\geq 15$ years), three parous and two nulliparous adult females ( $\geq 15$ years), one adolescent female (10-15 years), and four infants and juveniles ( $<10$ years); the larger community Kokoalongo comprised 45 individuals including eight adult males, 13 parous and four nulliparous adult females, two adolescent males, and 18 infants and juveniles. All community members were individually identified and were habituated to researchers' presence before the onset of the study. To minimize observer bias, blinded methods were used when all behavioral data were collected and analyzed.

\section{Data collection and analysis}

\section{Ranging behavior and social measures}

We followed parties of both communities simultaneously from the time they left their nests in the morning until they built their nests in the evening for an average of 27.5 days of nest-to-nest follows per group per month. During the follows, we recorded the geographic location automatically at 1-min intervals using GPS (Garmin GPS 62), from which we calculated the distance traveled by the focal party on a day. We recorded the identities of all adult and adolescent individuals present in the party over 30-min intervals to measure cumulative party composition (Mulavwa et al. 2008), and we calculated the daily mean party size as the daily average number of individuals present in the 30-min party compositions. We calculated a value of area marginality as a proxy for the degree of familiarity a community had with a given area of its home range as described in Lucchesi et al. (2020). For this calculation, we imposed a grid system of $1 \mathrm{~km}^{2}$ cells over the study area and calculated a value of marginality for each cell using the package "adehabitatHR" (version 0.4.14; Calenge 2011) in $\mathrm{R}$ (version 3.6.2; R Core Team 2018), which generates utilization distributions based on point density calculation from the daily tracklogs (Worton 1989). We then obtained daily values of marginality for each community by averaging the marginality values of the cells visited by the community on a given day weighted by the time spent in the cells. Increased values of marginality indicate a lower degree of utilization, and therefore a lack of familiarity, of a certain area. All data except for the geographic location were collected using the CyberTracker software (version 3.486).

Although in bonobos lone individuals may temporarily visit other communities, the dynamics of these visits typically differ from when larger groups decide to interact. This is particularly true for young nulliparous females exploring their possibilities to transfer from their natal social group (Sakamaki et al. 2015; Toda et al. 2018). During our study period, we observed only one adolescent female from Ekalakala temporarily visiting Kokoalongo, and we did not consider these instances as intercommunity associations. Rather, we recorded an encounter or association when an observer could see a minimum of two adult individuals from the focal community in the same party with a minimum of two adult individuals of another community.

\section{Feeding behavior and ecological measures}

During the daily party follows, we recorded all instances when members of the focal party visited trees and lianas (hereafter referred to as "fruit patches") to feed on their fruits and measured the diameter at breast height $(D B H)$ of these plants (i.e., the total cross-sectional area of the tree trunk measured at 1. $3 \mathrm{~m}$ above ground for trees and at $1.3 \mathrm{~m}$ above the level of the ultimate rooting point for lianas; Gerwing et al. 2006). To quantify feeding behaviors, we used instantaneous scan sampling by recording at 10 -min intervals the activity of all adult and adolescent individuals in view. If at least one bonobo in the party was feeding, we recorded the food type (fruit or THV) and the species eaten; if party members were feeding on different food items, we recorded the food eaten by the majority of the individuals (Gilby et al. 2010). From these data, 
we calculated the time spent feeding on fruits and on THV as the number of party scans in a day in which the majority of the individuals were feeding on the given food type corrected by observation effort (i.e., the total number of scans in that day). As a proxy for the availability of fruits in a given month, we used an improved version of the monthly fruit abundance index (FAI) calculated as in Lucchesi et al. (2020) for each community's home range. For this calculation, we combined data of tree and liana productivity from monthly phenology surveys on selected transects with data of tree and liana size and abundance from floristic plots as follows:

$\mathrm{MFAI}=\sum_{i}^{S} P_{\mathrm{im}} B_{i}$

In this equation, $P_{\mathrm{im}}$ is the proportion of trees of species $i$ in the phenology trail bearing ripe fruits in month $m, B_{i}$ is the basal area of species $i$ (i.e., the total cross-sectional area of tree trunks measured at $1.3 \mathrm{~m}$ above ground derived from the plots' data; see above), and $S$ is the total number of species included in the analysis. Since this equation as used in Lucchesi et al. (2020) returns a single MFAI value for each month (phenology surveys are done once per month in the beginning of each month), in order to approximate monthly FAI changes from month to month, for the present analyses, we calculated daily dFAI values as follows:

$\mathrm{dFAI}=A-\frac{(A-B)}{d} \times D$

In this equation, $A$ is the MFAI value of a given month, $B$ is the MFAI value of the following month, $d$ is the number of days in a given month, and $D$ is the day of the month for which the dFAI value is calculated.

\section{Dominance rank}

Dominance relationships among community members have been shown to influence individuals' energy balance in bonobos (Surbeck et al. 2015). Therefore, we assessed dominance relationships among all adult and adolescent individuals, without separating the sexes for the calculation, based on the outcome of dyadic agonistic interactions recorded on an ad libitum basis, classifying subordinates as those individuals exhibiting submission in response to aggression (e.g., fleeing upon aggression received) (Vervaecke et al. 2000; Surbeck et al. 2015). We determined a hierarchical rank order for the members of each community separately using the randomized Elo-rating score (Sanchez-Tojar et al. 2018) and normalized the resulting ranks between one (lowest rank) and zero (highest rank). As the amount of observations of agonistic interactions among the females was small $(N=53)$, we tested the validity of our estimated dominance hierarchies by simulating ten dominance matrices with the same number of individuals and the same number of agonistic interactions and missing dyads (i.e., dyads for which we did not observe an aggression-submission event: 60 missing dyads of 132 total dyads for Ekalakala and 158 missing dyads of 702 total dyads for Kokoalongo) as in our dataset (Surbeck and Hohmann 2013). The likelihood of winning an interaction was proportional to the absolute rank difference between the opponents. These simulations revealed a strong correlation between the resulting dominance hierarchies, thereby legitimizing our inference of dominance rank (Ekalakala dominance hierarchies: mean correlation coefficient $=0.95$, range: $0.88-1.00$; Kokoalongo dominance hierarchies: mean correlation coefficient $=0.97$, range: 0.94-0.99).

\section{Urine collection and sample selection}

We collected urine samples for the measurements of UCP levels opportunistically from identified individuals during daily party follows. We used the underside of large Marantaceae leaves to collect the urine before it touched the ground or, when this was not possible, by pipetting the urine from undergrowth foliage. In order to avoid cross-contamination, we did not collect urine that entered in contact with feces nor from vegetation already contaminated by urine from other individuals (Higham et al. 2011). All samples were frozen in liquid nitrogen within $12 \mathrm{~h}$ of collection and shipped frozen on dry ice to the Endocrinology Laboratory at the Max Planck Institute for Evolutionary Anthropology (MPI-EVA) in Leipzig, Germany, where they were stored at $-20{ }^{\circ} \mathrm{C}$ until analyzed. For the analyses, we selected only samples collected early in the morning (mean collection time $=6: 00 \mathrm{a} . \mathrm{m} . \pm$ $40 \mathrm{~min}, \mathrm{SD}$ ), as they likely reflect the energy balance of the previous day (Surbeck et al. 2015; Wessling et al. 2018). Since insulin production increases during pregnancy in mothers to ensure fetal glucose alimentation (Spellacy et al. 1965), we did not include samples of pregnant females. To obtain a temporally balanced dataset between intercommunity associations and non-associations, we selected for each sample collected after an association day (association sample) a matching sample from the same individual within 20 days collected after a non-association day (non-association sample). If no such non-association sample existed, we selected a non-association sample from another individual of the same sex which was collected within 10 days of the given association sample. We then balanced the number of samples across individuals by adding non-association samples to our pool to achieve even temporal coverage.

\section{UCP measurement}

Frozen urine samples were thawed at room temperature, shaken for $10 \mathrm{~s}$ (VX-2500 Multi-tube Vortexer), and centrifuged for $10 \mathrm{~min}$ at $2000 \mathrm{~g}$ (Multifuge Heraeus). We measured UCP 
levels with a commercially available immunoassay kit (CPep-EASIA KAP0401, DIAsource) validated for bonobo urine (Surbeck et al. 2015). Intra-assay coefficients of variation $(\mathrm{CV})$ were $2.08 \%$ and $1.69 \%$ for low- and high-value quality controls respectively, and inter-assay CVs were $3.21 \%$ and $4.87 \%$ for low- and high-value quality controls. If sample duplicates differed by more than $10 \%$ or measurements were outside of the assay's linear range, we remeasured the urine sample and, if needed, diluted the sample. To control for variation in urinary concentration, we corrected UCP levels by specific gravity (SG) measured with a digital handheld refractometer (Tec, Olber-Ramstadt, Germany) (Miller 2004). We excluded from the analyses three samples with SG below 1.002 as SG values below this threshold do not allow for a reliable correction for urine concentration (Löhrich et al. 2018). In sum, we successfully measured UCP levels in 330 samples from adult individuals $(N=27$ individuals, $N=$ 126 association samples, $N=204$ non-association samples).

\section{Statistical analysis}

\section{Energetic status (measured as UCP levels) of individuals relative to intercommunity associations}

To evaluate whether associations correlated with variation in the energy balance of participants (proxied by variation in individuals' UCP levels), we used a linear mixed model with Gaussian error structure (LMM; Baayen et al. 2008) with UCP levels as the response variable. We log transformed UCP levels as they were highly skewed at the original scale and found this transformation fulfilled the model's assumptions of normally distributed and homogeneous residuals. We included whether the previous day was an association day (yes/ no) as test predictor in a three-way interaction with the familiarity of the focal community with the area (intra-community marginality) and the familiarity of the other community with the same area (extra-community marginality). We considered intra-community and extra-community marginality relevant to the relationship between associations and UCP levels, because we previously found that the communities were less likely to terminate associations in less familiar areas of their home range (Lucchesi et al. 2020). This interaction therefore serves as a test of whether the presence of extra-community members in the party influenced the energy balance of individuals depending on the respective degree of familiarity the two communities had with an area. Additionally, we controlled for the potential effect of the sex and the dominance rank of the individual, fruit abundance index (dFAI), daily travel distance, party size, and community identity on the response. Finally, we included the random effects of individual ID and date of urine collection to account for uneven sampling and repeated measures of the same individual. We included the random slopes for the effects of individual ID on encounter, party size, travel distance, $\mathrm{dFAI}$, and intra-community and extra-community marginality.

\section{Travel distance relative to intercommunity associations}

To evaluate whether the distance traveled by the bonobos on a day varied according to whether that day was an association or a non-association day, we used a linear model with Gaussian error structure (LM; Fox and Weisberg 2011) with travel distance on a given day as the response variable, and we included a test predictor structure identical to that of the previous model. We controlled for the potential effects of $d F A I$, number of visited fruit patches, party size, and community identity on the response. Additionally, we controlled for potential temporal autocorrelation to account for the likelihood that travel distances were similar on days in close temporal proximity (Samuni et al. 2020). We first fitted a model including all predictors to obtain model residuals. Using model residuals, we then calculated an autocorrelation term for each data point as the average residual of all other data points weighted by their time difference to this data point, with the weighting function being a normal distribution whose standard deviation was determined by maximizing the likelihood of the model with the autocorrelation term included.

As longer travel distances may increase the chance of an encounter as well as be a consequence of this event, we conducted an additional post hoc analysis (LMM) to evaluate whether the distance traveled on the first day of an association differed from that traveled on the following days. If longer travel distances resulted in the occurrence of more encounters, we expected the travel distance on the day when the communities met (first day of association) to be longer than the travel distance on the following days of an association when the communities already traveled together. If travel distance remained high once the communities had already met, it follows that the longer travel distance measured during associations was a consequence of traveling together. Finally, if the travel distance was longer on the last day of an association, it may be the result of communities walking away from each other after separating. The model had identical structure as that described above (albeit with the additional random effect of encounter $I D$ ), but instead of evaluating the correlation between travel distance and association condition (yes/no), we evaluated the relation between travel distance and the different levels of the test predictor association day (levels: "first," "following," and "last day" of association, with "following day" as the reference value).

Finally, to contextualize the impact of potential differences in travel distances on energy expenditure, we applied the calculation from Pontzer and Wrangham (2004), which uses the equation from Taylor and Heglund (1982) that calculates the energy spent on terrestrial travel in primates: 
$\mathrm{O}_{2} \times M^{-1} \times s=0.523 M^{-0.298} V+0.345 M^{-0.157}$

In this equation, $\mathrm{O}_{2}$ is oxygen, $M$ is the body mass, $s$ is the walking distance, and $V$ is the walking speed. Oxygen is converted in kilocalories as: 1 liter $\mathrm{O}_{2}=4.8 \mathrm{kCal}$. For the calculation, we used the body mass of bonobos from Lola ya Bonobo (DRC) averaged across sexes and all age classes from Yapuncich et al. (2020).

\section{Number and size (DBH) of fruit patches visited relative to intercommunity associations}

To evaluate whether the number of fruit patches the bonobos visited during a day differed according to association condition (yes/no), we used a generalized linear model with Poisson error structure (GLM; Baayen et al. 2008). We included the number of fruit patches visited during a day as the response variable, and we included a test predictor structure identical to that of the previous models. We controlled for the potential effects of $d F A I$, party size, daily travel distance, average $D B H$ of the fruit patches visited in the day, and community identity on the response. As bonobos fed on both arboreal and liana fruits, but the DBH of the two vegetation types are categorically different, we normalized the measured DBHs of each type relative to their potential maximum value. To do so, we calculated a "maximum DBH" as the mean DBH of all trees and lianas, respectively, +2 standard deviations in order to account for the presence of outliers, as a few exceptional liana species may grow to maturity to a DBH similar to that of trees, thereby restricting our ability to account for average difference in these vegetation types (i.e., tree and liana). We then divided the DBH of each individual by the "maximum DBH" for each vegetation type. The average normalized $\mathrm{DBH}$ was 0.47 (i.e., $47 \%$ of the "maximum DBH") (range: 0.03-1.74) for trees and 0.29 (i.e. $29 \%$ of the "maximum DBH") (range: 0.04 4.11) for lianas. Finally, we included a temporal autocorrelation term calculated as above.

To evaluate whether the size of the visited fruit patches differed during association days and non-association days, we used an LM. We included the actual $D B H$ of each tree and liana visited on a given day as the response variable, and we included a test predictor structure identical to that of the previous models. We controlled for the potential effects of party size, community identity, and vegetation type (i.e., whether the species was a tree or a liana) on the response.

While bonobos may feed on larger fruit patches during associations to offset potential energetic costs of these events, larger fruit patches may also attract members of different communities which in turn favors the occurrence of encounters. Therefore, we conducted additional post hoc analyses (GLMM and LMM respectively) similar to the one we conducted for the travel distance in order to clarify whether the number and size of fruit patches visited on the first day of an association were different from those of the patches visited on the following days. If the selection of large fruit patches was a strategy to actively offset energetic costs of associations and not only an environmental circumstance promoting encounters between multiple communities, we expected the size of the fruit patches to remain large not only on the first day of an association but also on all following days. As above, we evaluated the relation between the response and the different levels of the test predictor association day (levels: "first," "following," and "last day" of association, with "following day" as the reference value).

\section{Time spent feeding on fruits and on THV relative to intercommunity associations}

To evaluate whether the time bonobos spent feeding per day differed according to association condition (yes/no) and whether they specifically targeted high energy food (fruits) or fed indiscriminately also on low energy food (THV) on association days, we used two GLMs with beta error structure (Cribari-Neto and Zeileis 2010). As response variable, we included the proportion of daily scans the majority of the party was feeding on fruits on a given day in the first model and the proportion of daily scans the majority of the party was feeding on THV in the second model. These responses were transformed as for Cribari-Neto and Zeileis (2010) so to not have values exactly equal to 0 and 1 . In both models, we included a test predictor structure identical to that of the previous models, and we controlled for the potential effects of $d F A I$, party size, and community identity on the response. We again included a temporal autocorrelation term calculated in the same manner as above.

As a party that spends a longer time feeding in a fruit patch may be more likely to encounter another party, we conducted an additional post hoc analysis (GLMM) to evaluate whether the time spent feeding on association days depended on whether the day was the first day of an association or a subsequent day. If increasing the time spent feeding on association days was an active strategy to offset potential energetic costs of associations, we expected that the time spent feeding remained high not only on the first day of an association but also on the following days (therefore, no difference in time spent feeding over the duration of multi-day associations). As above, we evaluated the relation between the response and the different levels of the test predictor association day (levels: "first," "following," and "last day" of association, with "following day" as the reference value).

\section{Model implementation}

Details of the structure of all models can be found in the Supplementary Material. All models were fitted in R (version 
3.5.0; R Core Team 2018) using the functions $l m$, lmer, and glmer of the R package "lme4" (version 1.1-17; Bates et al. 2014) with the optimizer bobyqa for the Gaussian and Poisson models and the function $\operatorname{glmmTMB}$ of the R package "glmmTMB" (version 1.0.2.1; Magnusson et al. 2020) for the Beta models. Prior to fitting the models and in order to reduce the influence of outliers, we square root-transformed the dominance rank values, the DBH values, and the intracommunity and extra-community marginality. We than normalized all predictors by $z$-transforming them to a mean of zero and a standard deviation of one to facilitate the interpretability of the resulting estimates (Schielzeth 2010). To keep type I error rate at the nominal level of 5\% (Schielzeth and Forstmeier 2009; Barr et al. 2013), we included all random slopes when applicable, allowing for the effects of the fixedeffects predictors to randomly vary among the levels of the random effect variable. For the Gaussian models, in order to verify the assumptions of normally distributed and homoscedastic residuals, we visually inspected q-q plots and the distribution of the residuals plotted against the fitted values, and we did not find any deviations from these assumptions for all models. For the GLMMs, we verified that each model did not suffer from overdispersion (Cameron and Trivedi 1990). We assessed model stability for each model by omitting each level of random effects one at a time and comparing the derived model estimates with those of the full model; we found no influential cases. In order to rule out collinearity, we evaluated variance inflation factors (VIF, Field 2005) with the function vif of the R package "car" (Fox and Weisberg 2011) for standard linear models excluding the random effects and the interactions (if present). We only found collinearity issues in the model investigating the relationship between associations and the number of visited fruit patches between the predictors DBH $(\mathrm{VIF}=4.97)$ and community identity $(\mathrm{VIF}=$ 5.2). We therefore removed each of these terms from the model one at a time, finding results almost identical to those of the model with both terms included (we report in Table 1 the results for the model excluding community identity and in the Supplementary Material, Table S1, the results for the model with both terms included and the model excluding DBH). Once we removed the collinear terms, the largest VIF among all models was 2.91 (Field 2005).

As an initial test of significance, we compared each full model including all predictors with its respective null model including only the random effects and the control predictors (Forstmeier and Schielzeth 2011), using a likelihood ratio test (R function anova with argument test set to "Chisq"; Dobson 2002). If the full model was significant against the null model, we proceeded to test the individual predictors with fixed effect by excluding each predictor one at a time and comparing this reduced model to the respective full model with a likelihood ratio test (Barr et al. 2013). As none of the three-way interactions reached significance (i.e., $p \leq 0.05$ ), we removed them from all models and only tested the respective lower order interaction terms. Confidence intervals were derived using the functions confint and bootMer of the package "Ime4," using 1000 parametric bootstraps and bootstrapping also over the random effects. The means and standard deviations of the square root-transformed predictors before the $z$-transformation are reported in the Supplementary Material, Table S2.

\section{Results}

During the study period, we followed the Ekalakala community for 415 days and the Kokoalongo community for 364 days, recording a total of 181 days of association between them. The duration of these associations varied extensively, ranging from brief encounters of less than an hour to longlasting associations of several consecutive days (average $=$ three consecutive days, range: 30 min-seven consecutive days). During associations, the mean daily party size was $9.7 \pm 3.1$ (SD) individuals (range: $2-21$ ), as opposed to a mean daily party size of $6.3 \pm 2.3$ (SD) individuals for Ekalakala (range: 2-9) and of $8.0 \pm 4.0$ (SD) individuals for Kokoalongo (range: 3-21) on non-association days. Moreover, while the members of Ekalakala were markedly cohesive and ranged predominately in a single party ( $91 \%$ of community members were observed on average during a follow day), members of Kokoalongo often fissioned into multiple parties (52\% of community members were observed on average on a follow day). Monthly fruit abundance (FAI) did not significantly differ between the two communities' home ranges (likelihood ratio test: $\chi^{2}=0.77, \mathrm{df}=1, p=0.45$; see the Supplementary Material, Table S3), with a monthly average dFAI of $63.3 \pm 37.8$ (SD) (range: 15.7-125.7) for Ekalakala and $72.2 \pm 41.2$ (SD) (range: 18.9-138.7) for Kokoalongo. The total home range overlap over the study period was $29.46 \mathrm{~km}^{2}$, which comprised $62 \%$ of Ekalakala's total home range and $52 \%$ of Kokoalongo's total home range. The portion of the home range not shared with the neighboring study community was $17.9 \mathrm{~km}^{2}$ for Ekalakala and $26.46 \mathrm{~km}^{2}$ for Kokoalongo.

\section{Energetic status of individuals relative to intercommunity associations}

As expected, an increase in general fruit abundance (dFAI) was associated with increased individuals' UCP levels. However, associations between the two communities and the respective degree of familiarity of each community to an area were not associated with significant changes in individuals' UCP levels (Table 1). 
Table 1 Summary of the results of the models investigating the relation between intercommunity association, individuals' energy balance, and groups' ranging and feeding behaviors

\begin{tabular}{llllll}
\hline Est & SE & $p$ & Lower CI & Upper CI \\
\hline
\end{tabular}

Energy balance relative to intercommunity associations (UCP levels variation) (full-null model comparison: $\left.\chi^{2}=0.008, \mathrm{df}=1, p=0.78\right)$; sample size: 241

Travel distance (full-null model comparison: $\chi^{2}=25.45, \mathrm{df}=1, p<0.001$ ); sample size: 729

\begin{tabular}{|c|c|c|c|c|c|}
\hline Intercept & 6.25 & 0.09 & - & 6.06 & 6.43 \\
\hline Association $^{\mathrm{a}}$ & 0.86 & 0.17 & $<0.001$ & 0.52 & 1.19 \\
\hline FAI & 1.21 & 0.07 & - & 1.08 & 1.34 \\
\hline Party size & 0.07 & 0.06 & - & -0.06 & 0.20 \\
\hline 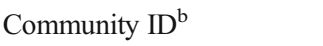 & 0.13 & 0.12 & - & -0.11 & 0.36 \\
\hline No. of visited fruit patches ${ }^{c}$ & 0.24 & 0.06 & - & 0.12 & 0.37 \\
\hline In-group marginality $^{\mathrm{c}}$ & 0.08 & 0.06 & - & -0.04 & 0.19 \\
\hline Out-group marginality ${ }^{c}$ & 0.13 & 0.06 & - & 0.02 & 0.24 \\
\hline Autocorrelation term & 3.13 & 0.20 & - & 2.73 & 3.53 \\
\hline
\end{tabular}

Number of visited fruit patches (full-null model comparison: $\chi^{2}=46.66, \mathrm{df}=1, p<0.001$ ); sample size: 296

$\begin{array}{lrrlrc}\text { Intercept } & -12.60 & 0.87 & - & -14.32 & -10.91 \\ \text { Association }^{\mathrm{a}} & -0.36 & 0.05 & <0.001 & -0.46 & -0.26 \\ \text { FAI } & -0.35 & 0.04 & - & -0.42 & -0.28 \\ \text { Party size } & -0.06 & 0.03 & - & -0.11 & -0.001 \\ \text { Travel distance }^{\text {Avg DBH }} & 0.14 & 0.03 & - & 0.09 & 0.19 \\ \text { In-group marginality }^{\mathrm{c}} & 0.08 & 0.03 & - & 0.02 & 0.13 \\ \text { Out-group marginality }^{\mathrm{c}} & 0.03 & 0.02 & - & -0.02 & 0.08 \\ \text { Autocorrelation term } & -0.02 & 0.02 & - & -0.07 & 0.03 \\ & -243.28 & 14.47 & - & -271.83 & -215.13\end{array}$

DBH of visited fruit patches (full-null model comparison: $\chi^{2}=10.38, \mathrm{df}=1, p=0.002$ ); sample size: 2297

$\begin{array}{lrrlrr}\text { Intercept } & 10.42 & 0.87 & - & 8.70 & 12.12 \\ \text { Encounter }^{\mathrm{a}} & 3.53 & 1.10 & 0.001 & 1.38 & 5.69 \\ \text { Party size } & -0.63 & 0.52 & - & -1.63 & 0.37 \\ \text { Community ID }^{\mathrm{b}} & 1.21 & 1.00 & - & -0.76 & 3.17 \\ \text { In-group marginality }^{\mathrm{c}} & 0.53 & 0.45 & - & -0.35 & 1.41 \\ \text { Out-group marginality }^{\mathrm{c}} & 0.38 & 0.45 & - & -0.49 & 1.26 \\ \text { Vegetation type }^{\mathrm{d}} & 30.82 & 0.89 & - & 29.07 & 32.57\end{array}$

Time spent feeding on fruits (full-null model comparison: $\chi^{2}=14.17, \mathrm{df}=1, p<0.001$ ); sample size: 294

$\begin{array}{lcccrr}\text { Intercept } & -2.09 & 0.09 & - & -2.27 & -1.92 \\ \text { Association }^{\mathrm{a}} & 0.33 & 0.05 & 0.01 & 0.07 & 0.60 \\ \text { FAI } & 0.51 & 0.07 & - & 0.37 & 0.65 \\ \text { Party size } & <0.001 & 0.05 & - & -0.11 & 0.11 \\ \text { Community ID }^{\mathrm{b}} & -0.09 & 0.11 & - & -0.30 & 0.12 \\ \text { In-group marginality }^{\mathrm{c}} & 0.003 & 0.05 & - & -0.10 & 0.10 \\ \text { Out-group marginality }^{\mathrm{c}} & -0.01 & 0.05 & - & -0.11 & 0.08 \\ \text { Autocorrelation term } & 15.88 & 1.25 & - & 13.44 & 18.33\end{array}$

Time spent feeding on THV (full-null model comparison: $\chi^{2}=1.26, \mathrm{df}=1, p=0.76$ ); sample size: 294

Significant test predictors $(p \leq 0.05)$ are indicated in italic, $p$ values for control predictors are not reported. The effects of individual predictors are not reported when the full-null model comparison did not reach significance $(p \leq 0.05)$

a The reference level for association (yes/no) is "yes"

b The reference value for community ID (Kokoalongo/Ekalakala) is "Kokoalongo"

${ }^{\mathrm{c}}$ Predictors were square root-transformed

d The reference value for vegetation type (tree/liana) is "tree" 


\section{Travel distance relative to intercommunity associations}

The bonobos traveled significantly longer distances during association than non-association days independent of the total number of individuals present, the number of fruit patches they visited, and the familiarity they had with an area of their home range (Table 1, Fig. 1). On average, the communities traveled $8.14 \pm 1.9(\mathrm{SD}) \mathrm{km}$ (range: $1.8-14.1 \mathrm{~km}$ ) on association days, while they traveled $6.01 \pm 2.25$ (SD) $\mathrm{km}$ (range: $1-$ 12.7) on non-association days. During association days, the distance the bonobos traveled on the first day of an association did not significantly differ from the distance traveled on any of the following days of association (full-null model comparison: $\chi^{2}=3.73, \mathrm{df}=3, p=0.29$ ) (see the Supplementary Material, Table S4).

On average, the bonobos spent 69 more kcal by walking longer distances on association days (mean energy spent by walking: $264.48 \pm 70.4$ (SD) kcal; range: $53.08-492.99 \mathrm{kcal}$ ) than on non-association days (mean energy spent by walking: $195.44 \pm 70.83 \mathrm{kcal}$; range: $43.58-424.84 \mathrm{kcal}$ ), which corresponds to a $35 \%$ increase of mean energy expenditure due to terrestrial travel on association days.

\section{Number and size (DBH) of visited fruit patches rela- tive to intercommunity associations}

The bonobos visited significantly fewer and larger fruit patches during association than non-association days independent of the total number of individuals present in the party and the distance traveled on the day (Table 1, Figs. 2 and 3). On average, the communities visited $6.6 \pm 4.2$ (SD) fruit patches

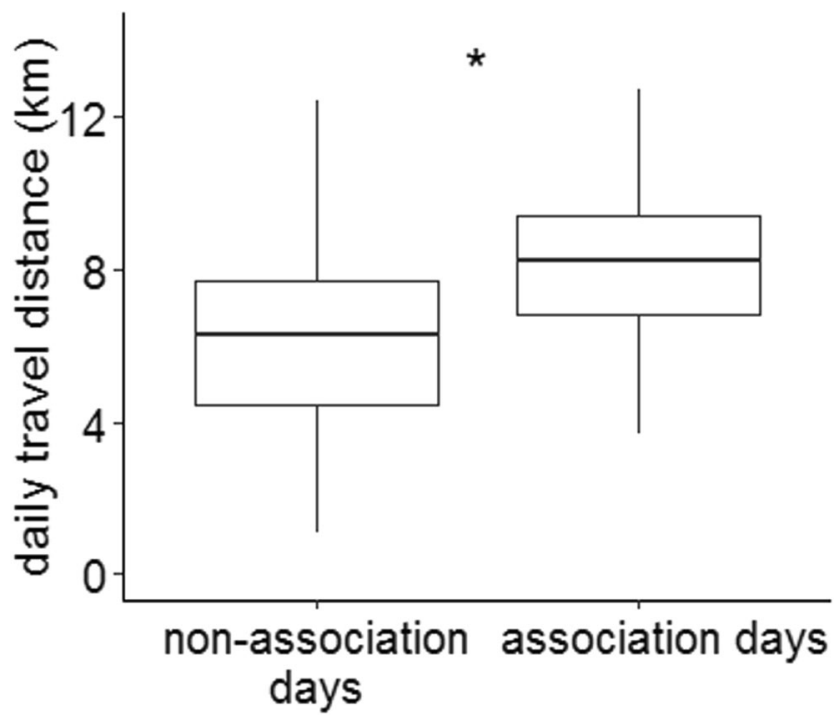

Fig. 1 Difference in the distance the bonobos traveled during nonassociation and association days. Shown are medians (thin horizontal lines), quartiles (boxes), and percentiles (vertical lines; $2.5 \%$ and $97.5 \%$ ). The asterisk indicates statistically significant difference

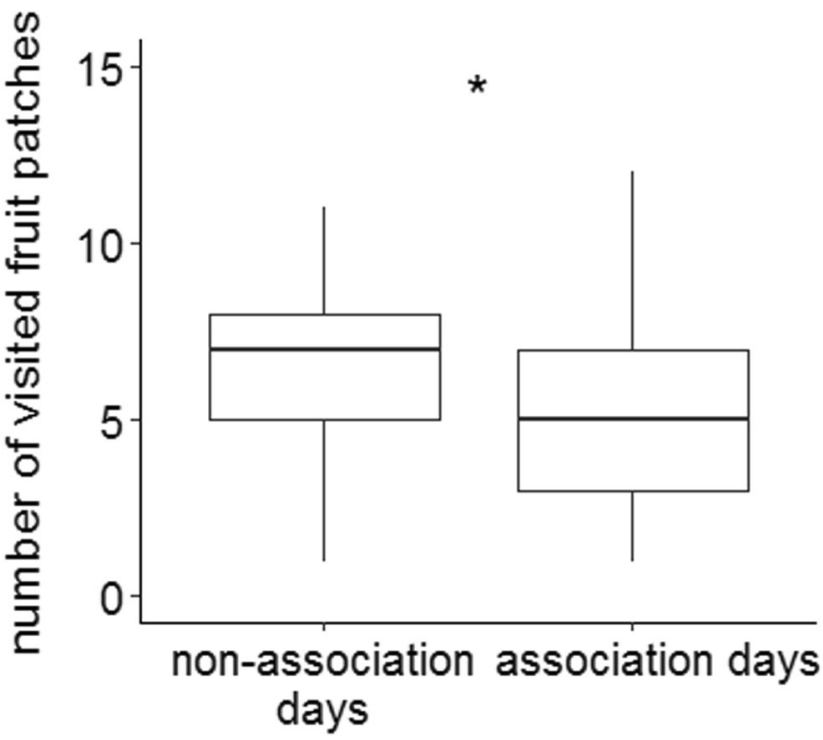

Fig. 2 Difference in the number of fruit patches visited on nonassociation and association days. Shown are medians (thin horizontal lines), quartiles (boxes), and percentiles (vertical lines; $2.5 \%$ and $97.5 \%$ ). The asterisk indicates statistically significant difference

(range: 1-30) on association days, while they visited $8.66 \pm$ 4.17 (SD) fruit patches (range: 1-36) on non-association days. The average DBH of the visited trees was $45.4 \pm 24.3$ (SD) $\mathrm{cm}$ (range: $5.41-124.14 \mathrm{~cm}$ ) on association days and $41.62 \pm$ 24.23 (SD) $\mathrm{cm}$ (range: $4.45-157.88 \mathrm{~cm}$ ) on non-association days, and the $\mathrm{DBH}$ of the visited lianas was $13.5 \pm 18.65(\mathrm{SD})$ $\mathrm{cm}$ (range: $3.5-124.46 \mathrm{~cm}$ ) on association days and $10.96 \pm$ 12.59 (SD) $\mathrm{cm}$ (range: $1.6-162.34 \mathrm{~cm}$ ) on non-association days.

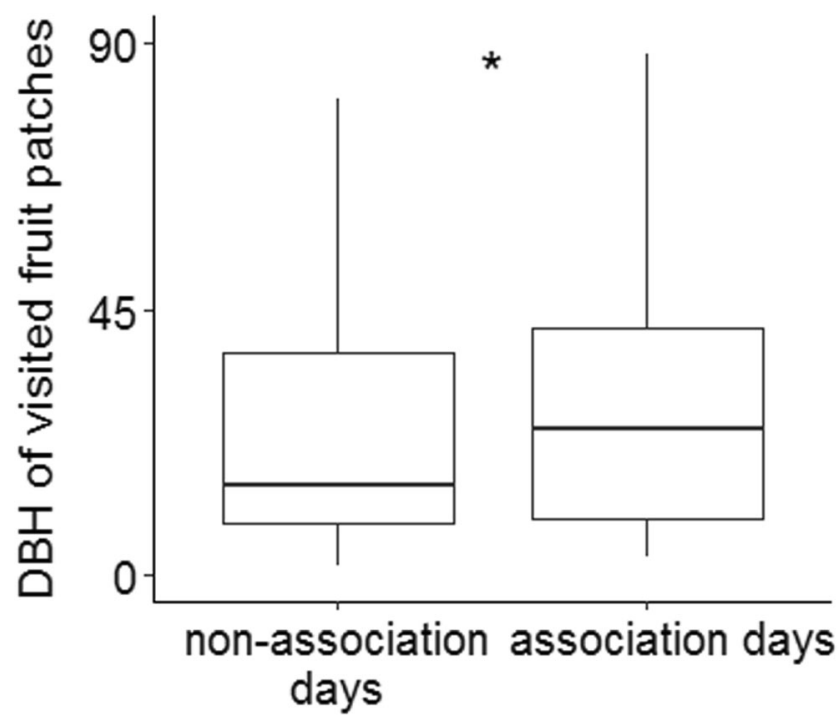

Fig. 3 Difference in the size (DBH) of the fruit patches on which the bonobos fed during non-association and association days. Shown are medians (thin horizontal lines), quartiles (boxes), and percentiles (vertical lines; $2.5 \%$ and $97.5 \%$ ). The asterisk indicates statistically significant difference 
During association days, the number (full-null model comparison: $\chi^{2}=3.6, \mathrm{df}=3, p=0.31$ ) and size (full-null model comparison: $\chi^{2}=1.21, \mathrm{df}=2, p=0.54$ ) of the fruit patches the bonobos visited on the first day of an association did not significantly differ from those visited on any of the following days of association (see the Supplementary Material, Tables S5 and S6).

\section{Time spent feeding on fruits and on THV relative to intercommunity associations}

The bonobos spent significantly more time feeding on fruits during association than non-association days independent of the number of individuals in the party, the familiarity to an area of the home range, and the general abundance of fruits in the forest (dFAI) (Table 1, Fig. 4), but there was no significant difference on the time they spent feeding on THV. On average, on association days the communities fed on fruits $57.7 \%$ $\pm 27.1 \%$ (SD) (range: $0-100 \%$ ) and on THV $23.1 \% \pm 23 \%$ (SD) (range: $0-100 \%$ ) of their feeding time, while on nonassociation days, they fed on fruits $41.8 \% \pm 33.3 \%$ (SD) (range: $0-100 \%$ ) and on THV $15.5 \% \pm 19.9 \%$ (SD) (range: $0-100 \%)$ of their feeding time.

During association days, the time the bonobos spent feeding on fruits on the first day of an association did not significantly differ from that of any of the following days of association (full-null model comparison: $\chi^{2}=0.44, \mathrm{df}=3, p=$ 0.93) (see the Supplementary Material, Table S7).

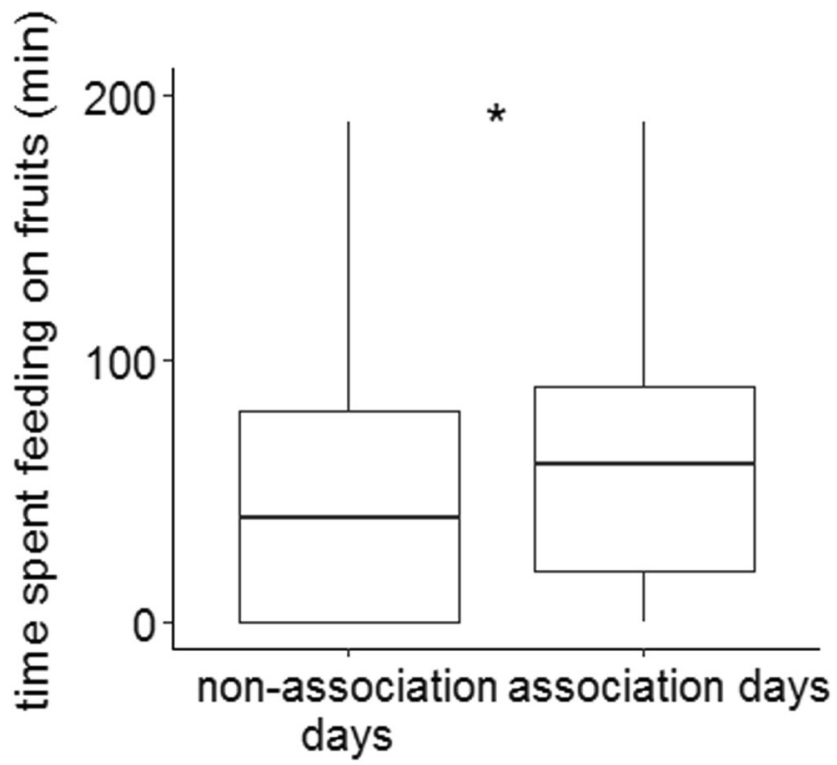

Fig. 4 Difference in the time the bonobos spent feeding on fruits (in minutes) during non-association and association days. Shown are medians (thin horizontal lines), quartiles (boxes), and percentiles (vertical lines; $2.5 \%$ and $97.5 \%$ ). The asterisk indicates statistically significant difference

\section{Discussion}

We investigated whether intercommunity associations in bonobos conferred clear energetic benefits to individuals, as measured by variation in UCP levels. We found that individuals participating in associations did not gain measurable net energetic benefits from these associations; thus, we did not find support for the energetic benefits hypothesis. We also found indications that associations carried energetic costs due to longer travel distances and that the bonobos actively offset these costs by visiting larger fruit patches and increasing the time spent feeding on fruits on association days. Although the exact nature of the benefits associations may provide to individuals remains unclear, the reported adaptations in feeding behavior in concomitance with the absence of obvious energetic benefits suggest that incentives other than energy acquisition (e.g., social benefits) contributed to the occurrence of tolerant associations between communities.

Bonobo communities are more likely to encounter each other at times when fruit resources are more abundant, a pattern consistent across populations (Sakamaki et al. 2018; Lucchesi et al. 2020). However, we found that after accounting for variation in fruit abundance, bonobos visited larger fruit patches and spent more time feeding on fruits throughout an association than on non-association days. These results indicate that a higher abundance of fruits was not a sufficient condition to allow associations to last for prolonged periods of time and that bonobos implemented additional strategies to offset the energetic costs of these associations by adapting their feeding behavior. Importantly, although these strategies (i.e., visiting larger feeding patches and increasing the time spent feeding on fruits) are similar to those adopted to reduce intra-group feeding competition, by controlling for the main parameter known to influence intra-group competition in our models (i.e., group size), we demonstrated that these strategies are in fact the result of challenges unique to associations and thus a fundamental component of the mechanisms allowing social networks to extend beyond the community level.

Associations carried a direct and measurable energetic burden to individuals due to longer travel distances. Generally, in group-living species, groups travel greater distances when their size is larger because a higher number of co-feeding individuals deplete feeding patches faster, thus forcing the group to move on to the next patch in order to meet individuals' energetic requirements (wedgecapped capuchin monkeys, Cebus olivaceus: Ruiter 1986; common cranes, Grus grus: Alonso et al. 1987; chimpanzees, P. troglodytes and spider monkeys, A. geoffroyi: Chapman et al. 1995; red colobus monkeys, P. badius: Gillespie and Chapman 2001). However, as we controlled for the influence of the numbers of competitors within a party in our models (proxied by the party size), it is unlikely that scramble competition explains the increased travel distances we measured. Instead, it appears 
that associations conferred unique burdens upon individuals, thereby leading participants to travel greater distances.

In some species, groups tend to increase their travel distance after an encounter has occurred (white-faced capuchin monkeys, C. capucinus: Crofoot 2013; African wild dogs, L. pictus: Jordan et al. 2017; mountain gorillas, G. beringei beringei: Seiler et al. 2018) or even before it occurred when a group finds clues that other groups are in proximity (chacma baboons, P. ursinus: Noser and Byrne 2007; African wild dogs, L. pictus: Parker 2010; lions, P. leo: Yiu et al. 2015). In the aforementioned cases, longer travel distances are generally due to avoidance behaviors resulting from agonistic intergroup relations. However, in Kokolopori, the high frequency and prolonged duration of associations suggest a higher likelihood of attraction between communities rather than avoidance (Lucchesi et al. 2020; LC et al. unpubl. data). In fact, although encounters can be aggressive in bonobos (Tokuyama et al. 2019; LC et al. unpubl. data), in Kokolopori, parties of different communities did not avoid each other even when their difference in size (and therefore their fighting abilities) was larger (Lucchesi et al. 2020). Conversely, parties often changed their travel direction towards individuals of the other community upon hearing their vocalizations (SL, unpublished data). Nevertheless, attraction or avoidance dynamics were unlikely to explain the observed increased travel distances. In fact, our results indicate there was no difference in the travel distance between the first day and the following days of an association. This result makes it unlikely that longer travel distances were the cause for the communities to encounter or were a consequence of avoidance behavior, but rather suggests that longer travel distances were a consequence of traveling in association.

One possible explanation for the increased travel distances we measured is that as associations are tense events for individuals (Tokuyama et al. 2019; LC unpubl. data), participating in an association may result in a less efficient use of resources, which may increase the overall travel distance during the day. Alternatively, as we observed that the number of visited fruit patches decreased during associations, it may be that the bonobos traveled longer distances during association days to target specific, larger fruit patches. Indeed, throughout the duration of an association, bonobos visited fewer fruit patches which were on average larger than on non-association days. It could be argued that a potential clumped distribution of these large fruit patches brought the communities together in the first place. However, in an earlier study, we found that clumpiness of fruit patches did not influence the probability of the communities to encounter. Rather, higher patches' clumpiness increased the likelihood of associations to terminate (Lucchesi et al. 2020). We therefore argue that the selection of large patches throughout the duration of a multi-day association was more likely to be a strategy for mitigating the energetic costs of these events rather than a consequence of spatial proximity of the patches. Similarly unlikely is that visiting larger fruit patches was a benefit of associations. In fact, our analyses ruled out the influence of information exchange about food location in unfamiliar areas, and it is hard to see any reason why individuals ranging in familiar areas should necessitate members of the other community to be able to locate large fruit patches.

As selection of larger fruit patches was independent of the size of the party, it may be that such a strategy was employed to decrease the level of contest competition within the patch rather than at compensating for decreased food intake due to increased scramble competition (Japanese macaques, Macaca fuscata: Saito 1996; Sumatran orangutans, Pongo abelii: Utami et al. 1997; vervet, Chlorocebus aethiops and patas, Erythrocebus patas monkeys: Pruetz and Isbell 2000; convict cichlids, Archocentrus nigrofasciatus: Kim et al. 2004; house sparrows, Passer domesticus: Johnson 2004). Examining how aggression rates vary in relation to patch size and the presence of extra-community members, and whether aggression is disproportionally directed to extra-community individuals, may help investigate the presence and level of contest competition between communities during associations. In this context, further investigation of whether associations tend to occur at specific trees or lianas with particular features (e.g., high nutritional value of the fruits, short fruits' processing time, or large number of feeding sites) will help to elucidate remaining uncertainties about the driving ecological factors of intergroup associations.

Further evidence supporting that Kokolopori bonobos employed strategies to offset potential energetic costs of associations is the increased time they spent feeding on fruits throughout the entire duration of an association. Indeed, that the time spent feeding on fruits but not on THV increased during associations suggests that the bonobos specifically targeted high energy foods when associating with the other community. Once again, scramble competition due to a larger number of co-feeders cannot serve as an explanation for this pattern as we controlled for party size in our models. Therefore, increasing the time spent feeding on fruits on association days may be a way for bonobos to offset the higher energetic requirements (i.e., an additional $35 \%$ caloric expenditure compared to non-association days) incurred by traveling longer distances. Detailed nutritional analyses of bonobos' daily caloric intake will help to further quantify the precise energetic burden that intercommunity associations impose upon individuals.

The employment of the aforementioned strategies to offset potential energetic costs of associations in order to prolong these events suggests that associations provide benefits to participants. We previously argued that associating with extra-community members was unlikely to be means for Kokolopori bonobos to buffer local resource shortfall by foraging in the neighbors' home range. Similarly unlikely is that these associations enabled 
one community to access energetically beneficial resources found outside their core range. Indeed, associations were not more likely to occur when fruit abundance decreased in the home range of the focal community (Lucchesi et al. 2020), nor were associations related to an increase in the energy balance of individuals. Moreover, since the presence of extra-community members in the party was not significantly related to changes in individuals' energetic balance when ranging in less familiar areas, nor was there indication that it helped individuals find larger fruit patches specifically in such areas, associations do not seem a likely strategy for information exchange about food location as has been observed in other species (hooded crows, C. corone cornix: Sonerud et al. 2001; short-tailed fruit bats, Carollia perspicillata: Ratcliffe and Hofstede 2005; graycheeked mangabeys, Lophocebus albigena: Janmaat et al. 2009; Janmaat and Chancellor 2010). Yet, communities were less likely to terminate associations when ranging in less familiar areas (Lucchesi et al. 2020). A possible explanation for this tendency is that individuals remained in association with members of the other community once they found themselves in less familiar areas for protection and to reduce stress in unfamiliar environments (Haemisch 1990). Investigating the likelihood of community members to range in less familiar areas with or without members of the other community, and the comparison of individuals' stress responses (e.g., variation in cortisol levels) in these two scenarios, may help investigate this possibility. It should be noted however that, although UCP patterns have previously been reported to correspond with short-term intra-diem variation in energy balance both in humans and in non-human primates (Cousin 1980; Meystas 1981; Georgiev 2012), we cannot completely exclude that UCPs may not be a fine scaled enough indicator to register subtle increases in energy balance imposed by associations.

Taken together, these results suggest that the benefits provided by associations in Kokolopori are unlikely related to improved food access and energy acquisition. In the absence of clear ecological benefits, it is reasonable to deduce that individuals obtained non-energetic benefits through intercommunity interactions, such as social benefits. While recent studies have described behavioral responses of bonobos to extracommunity members (Fruth and Hohmann 2018; Tokuyama et al. 2019), little is still understood about how these social interactions can benefit individuals and why individuals decide to participate in associations despite the presence of energetic costs that they need to offset. In many species, members of different groups associate with the purpose to increase the number of social (African elephants, L. africana: Wittemyer et al. 2005) and mating (Hanuman langurs, S. entellus: Launhardt et al. 2001; Verreaux's sifaka, $P$. verreauxi: Lawler 2007) partners or to evaluate the possibility of transfer from their natal group (meerkats, S. suricatta: Drewe et al. 2009). In bonobos, non-energetic benefits of associations may include extra-community paternities (but see
Ishizuka et al. 2018; Ishizuka et al. 2020), facilitation of the transfer of young nulliparous females or even males to other communities (Hohmann 2001; Sakamaki et al. 2015; Toda et al. 2018), and maintenance of social bonds among females of adjacent communities (Sakamaki et al. 2018). For instance, copulation between members of different communities is common during associations (Furuichi 2011; Lucchesi et al. 2020), and in previous research we have shown that communities are more likely to remain in association when the number of maximally tumescent females is high. However, the rarity of extra-community paternities in bonobos suggests that intercommunity copulations infrequently lead to the siring of offspring outside an individual's own social group (Ishizuka et al. 2018, 2020). Socio-sexual behavior is a hallmark trait of bonobos' behavioral repertoire. Its function includes potential social bonding (Brown 2005), reconciliation (Palagi et al. 2004), and tension regulation (Hohmann and Fruth 2000). It is possible that similar mechanisms also apply across communities, for instance by helping females of different communities support each other against males (suggested in Sakamaki et al. 2018 and Tokuyama et al. 2019). Research on the affiliative interactions between members of different communities, as well as on the different involvement of individuals of different sexes, may help elucidate which particular social benefits associations can provide.

If obtaining social benefits is the main motive promoting associations, a natural consequence is that the time individuals need to dedicate to social interactions may increase. This could potentially pose restriction to the time individuals can allocate to foraging (Dunbar 1991; Lehmann et al. 2007), which has been shown to be a factor posing a limit to the size a group can grow before fissioning (Henzi et al. 1997). However, socializing with members of the other community did not seem to translate in reduced time allocated to feeding in Kokolopori, where bonobos instead increased their foraging time during associations. This increase in feeding time suggests that bonobos were not time constrained during associations, likely because of high abundance of fruit resources in these periods. It follows that associations can occur when ecological conditions are favorable so that bonobos are not energetically constrained and can dedicate time both to feeding and to socializing with extra-community members. Detailed quantification on the time allocated to - and the types of - social interactions during associations, as well as studies on individuals' stress responses to extra-community members (e.g., by analysis of cortisol variation patterns), may help evaluate the respective challenging role of the social and the ecological environments during these events (LC et al. unpubl. data).

Lastly, the UCP levels we measured in Kokolopori bonobos were generally higher for both sexes than those measured in another bonobo population in LuiKotale (Surbeck et al. 2015; Nurmi et al. 2018), although they overlapped to some 
extent (individual UCP medians' range for females: LuiKotale $=1.49-3.30 \mathrm{ng} / \mathrm{mg}$ crea., Kokolopori $=2.97-$ $7.31 \mathrm{ng} / \mathrm{mg}$ crea.; individual UCP medians' range for males: LuiKotale $=0.98-2.80 \mathrm{ng} / \mathrm{mg}$ crea., Kokolopori $=1.54$ $5.56 \mathrm{ng} / \mathrm{mg}$ crea.). This difference in UCP levels between the two populations may be due to factors other than resource availability, such as different levels of competition with other frugivorous species at the two sites. Nevertheless, this difference in UCP levels between Kokolopori and LuiKotale suggests that environmental variability may have repercussions on the level of competition different populations face, which in turn affects the frequency and typology of encounters among adjacent communities. For instance, intercommunity encounters in LuiKotale are generally rarer and shorter than in Kokolopori (Fruth and Hohmann 2018), which may be linked to higher degrees of feeding competition in LuiKotale. Exploring the behavioral flexibility of bonobos by broadening research to additional wild populations with comparable data collection and analysis protocols will help to better understand how intergroup dynamics are rooted in particular characteristics of the habitat. This understanding may illuminate how environmental factors can promote behavioral diversity and, by doing so, contribute to shape intercommunity behavior.

Tolerance among groups is a necessary first step in the formation of complex multilevel societies, where social tiers are nested within each other (Rubenstein and Hack 2004; Wittemyer et al. 2005; Grueter et al. 2012; Snyder-Mackler et al. 2012). Similar to what is observed in most multilevel societies, favorable ecological conditions appear to be a central factor in allowing bonobo communities to come together (Sakamaki et al. 2018; Lucchesi et al. 2020) and the duration of associations likely depends on the social advantages individuals obtain from associating with extra-community members. However, whether a hierarchical organization above the community level exists in bonobos, or the social system of the species is a highly modular organization without strictly defined social tiers, is still unclear. Either way, advancing our knowledge on the motives and strategies social groups of bonobos adopt to maintain tolerant relationships with each other is a central contribution in understanding the mechanisms through which social networks can extend beyond and across groups in social-living species.

Supplementary Information The online version contains supplementary material available at https://doi.org/10.1007/s00265-020-02943-9.

Acknowledgments We thank the Bonobo Conservation Initiative, Vie Sauvage and ICCN, particularly Sally Coxe and Albert Lotana Lokasola for their efforts to support our work in the field. We are grateful to the Ministry of Scientific Research and Technology of the Democratic Republic of the Congo for permitting our research in Kokolopori Bonobo Reserve. Many thanks to Claudia Wilke, Axel Martínez Ruiz, and Maelle Lemaire for their help in the field and particular thanks to Leonard Nkanga and the team of local assistants for their invaluable contribution to data collection and bonobo tracking. We also thank two anonymous reviewers and the Associate Editor Dr. Kevin Langergraber for valuable comments on an early version of this manuscript.

Funding Open Access funding enabled and organized by Projekt DEAL. This work was supported by Harvard University, the Max Planck Institute for Evolutionary Anthropology, and by the Leakey Foundation.

Data availability The datasets generated and analyzed during the current study are available in the Figshare repository at https://oi.org/10.6084/ m9.figshare. 13177172 .

\section{Compliance with ethical standards}

Conflict of interest The authors declare that they have no competing interests.

Ethics approval All methods applied were strictly non-invasive. Permits to conduct research at the Kokolopori Bonobo Reserve, Democratic Republic of the Congo, were granted by the Ministry of Research of the Democratic Republic of the Congo. All applicable international, national, and institutional guidelines for the use of animals were followed.

Consent to participate Not applicable.

Consent for publication Not applicable.

Code availability Not applicable.

Open Access This article is licensed under a Creative Commons Attribution 4.0 International License, which permits use, sharing, adaptation, distribution and reproduction in any medium or format, as long as you give appropriate credit to the original author(s) and the source, provide a link to the Creative Commons licence, and indicate if changes were made. The images or other third party material in this article are included in the article's Creative Commons licence, unless indicated otherwise in a credit line to the material. If material is not included in the article's Creative Commons licence and your intended use is not permitted by statutory regulation or exceeds the permitted use, you will need to obtain permission directly from the copyright holder. To view a copy of this licence, visit http://creativecommons.org/licenses/by/4.0/.

\section{References}

Alonso JC, Alonso JA, Veiga JP (1987) Flocking in wintering common cranes Grus grus: influence of population size, food abundance and habitat patchiness. Ornis Scand 18:53-60

Amsler SJ (2009) Energetic costs of territorial boundary patrols by wild chimpanzees. Am J Primatol 7:93-103

Bayen R, Davidson D, Bates D (2008) Mixed-effects modeling with crossed random effects for subjects and items. J Mem Lang 59: 390-412

Barr D, Levy R, Scheepers C, Tily H (2013) Random effects structure for confirmatory hypothesis testing: keep it maximal. J Mem Lang 68: 255-278

Bates D, Mächler M, Bolker B, Walker S (2014) Fitting linear mixedeffects models using lme4. J Stat Softw 67:1-48

Bisther A (2002) Intergroup interactions among killer whales in Norwegian coastal water; tolerance vs. aggression at feeding grounds. Acquat Mamm 28(1):14-23 
Boydston EE, Morelli TL, Holekamp KE (2001) Sex differences in territorial behavior exhibited by the spotted hyena (Hyaenidae, Crocuta crocuta). Ethology 107:369-385

Brotons L, Herrando S (2003) Effect of increased food abundance near forest edges on flocking patterns of coal tit Parus ater winter groups in mountain coniferous forests. Bird Study 50:106-111

Brown CR (1988) Enhanced foraging efficiency through information centers: a benefit of coloniality in cliff swallows. Ecology 69:602613

Brown P (2005) Socio-sexual behaviour in two groups of captive bonobos (Pan paniscus): a description and functional analysis. $\mathrm{PhD}$ thesis, Durham University

Brown M (2013) Food and range defence in group-living primates. Anim Behav 85:807-816

Calenge C (2011) Home range estimation in R: the adehabitath R package. https://citeseerx.ist.psu.edu/viewdoc/download?doi=10.1.1. 303.8458\&rep=rep1\&type $=$ pdf. Accessed 16 Jan 2019

Cameron M (2006) Group size and feeding rates of glossy blackcockatoos in Central New South Wales. Emu 105:299-304

Cameron AC, Trivedi PK (1990) Regression-based tests for overdispersion in the Poisson model. J Econom 46:347-364

Cashdan E, Barnard A, Bicchieri M et al (1983) Territoriality among human foragers: ecological models and an application to four bushman groups. Curr Anthropol 24:47-66

Chapman CA, Valenta K (2015) Costs and benefits of group living are neither simple nor linear. P Natl Acad Sci USA 112:14751-14752

Chapman CA, Chapman LJ, Wrangham RW (1995) Ecological constraints on group size: an analysis of spider monkey and chimpanzee subgroups. Behav Ecol Sociobiol 36:59-70

Clapham PJ, Palsbøll PJ, Mattila DK, Vasquez O (1992) Composition and dynamics of humpback whale competitive groups in the West Indies. Behaviour 122:182-194

Cribari-Neto F, Zeileis A (2010) Beta regression in R. J Stat Softw 34:124

Crofoot MC (2013) The cost of defeat: capuchin groups travel further, faster and later after losing conflicts with neighbors. Am J Phys Anthropol 152:79-85

Cvikel N, Berg KE, Levin E, Hurme E, Borissov I, Boonman A, Amichai E, Yovel Y (2015) Bats aggregate to improve prey search but might be impaired when their density becomes too high. Curr Biol 25:206211

Dasilva GL (1992) The Western black-and-white colobus as a lowenergy strategist: activity budgets, energy expenditure and energy intake. J Anim Ecol 61:79-91

Deschner T, Kratzsch J, Hohmann G (2008) Urinary c-peptide as a method for monitoring body mass changes in captive bonobos (Pan paniscus). Horm Behav 54:620-626

Dobson A (2002) An introduction to generalized linear models. Chapman $\&$ Hall/CRC, London

Drewe JA, Madden JR, Pearce GP (2009) The social network structure of a wild meerkat population: 1. Inter-group interactions. Behav Ecol Sociobiol 63:1295-1306

Dubois F, Giraldeau L (2003) The forager's dilemma: food sharing and food defense as risk-sensitive foraging options. Am Nat 162:768 779

Dunbar RIM (1991) Functional significance of social grooming in primates. Folia Primatol 57:121-131

Ellis S, Franks DW, Robinson EJH (2014) Resource redistribution in polydomous ant nest networks: local or global? Behav Ecol 25: $1183-1191$

Emery Thompson M (2017) Energetics of feeding, social behavior, and life history in non-human primates. Horm Behav 91:84-96

Field A (2005) Discovering statistics using SPSS. Sage Publications, London
Forstmeier W, Schielzeth H (2011) Cryptic multiple hypotheses testing in linear models: overestimated effect sizes and the winner's curse. Behav Ecol Sociobiol 65:47-55

Fox J, Weisberg S (2011) An R companion to applied regression, 2nd edn. Sage, Thousand Oaks

Fruth B, Hohmann G (2018) Food sharing across borders: first observation of intercommunity meat sharing by bonobos at LuiKotale, DRC. Hum Nat 29:91-103

Fry DP (2012) Life without war. Science 336:879-884

Furrer RD, Kyabulima S, Willems EP, Cant MA, Manser MB (2011) Location and group size influence decisions in simulated intergroup encounters in banded mongooses. Behav Ecol 22:493-500

Furuichi T (2011) Female contributions to the peaceful nature of bonobo society. Evol Anthropol 20:131-142

Furuichi T (2020) Variation in intergroup relationships among species and among and within local populations of African apes. Int $\mathrm{J}$ Primatol 41:203-223

Georgiev A (2012) Energetic costs of reproductive effort in male chimpanzees. $\mathrm{PhD}$ thesis, Harvard University

Gerwing JJ, Schnitzer SA, Burnham RJ, Bongers F, Chave J, DeWalt SJ, Ewango CEN, Foster R, Kenfack D, Martínez-Ramos M, Parren M, Parthasarathy N, Pérez-Salicrup DR, Putz FE, Thomas DW (2006) A standard protocol for liana censuses: short communications. Biotropica 38:256-261

Gese EM (2001) Territorial defense by coyotes (Canis latrans) in Yellowstone National Park, Wyoming: who, how, where, when, and why. Can J Zool 79:980-987

Gilby IC, Pokempner AA, Wrangham RW (2010) A direct comparison of scan and focal sampling methods for measuring wild chimpanzee feeding behaviour. Folia Primatol 81:254-264

Gillespie TR, Chapman CA (2001) Determinants of group size in the red colobus monkey (Procolobus badius): an evaluation of the generality of the ecological-constraints model. Behav Ecol Sociobiol 50: 329-338

Girard-Buttoz C, Higham JP, Heistermann M, Wedegärtner S, Maestripieri D, Engelhardt A (2011) Urinary C-peptide measurement as a marker of nutritional status in macaques. PLoS One 6: e18042

Grant JWA (1993) Whether or not to defend? The influence of resource distribution. Mar Behav Physiol 23:137-153

Grueter CC, Matsuda I, Zhang P, Zinner D (2012) Multilevel societies in primates and other mammals: introduction to the special issue. Int $\mathrm{J}$ Primatol 33:993-1001

Grueter CC, Deschner T, Behringer V, Fawcett K, Robbins MM (2014) Socioecological correlates of energy balance using urinary Cpeptide measurements in wild female mountain gorillas. Physiol Behav 127:13-19

Haemisch A (1990) Coping with social conflict, and short-term changes of plasma cortisol titers in familiar and unfamiliar environments. Physiol Behav 47:1265-1270

Henzi SP, Lycett JE, Weingrill T (1997) Cohort size and the allocation of social effort by female mountain baboons. Anim Behav 54:12351243

Herbinger I, Boesch C, Rothe H (2001) Territory characteristics among three neighboring chimpanzee communities in the Ta1 National Park, Cote d'Ivoire. Int J Primatol 25:143-167

Higham JP, Girard-Buttoz C, Engelhardt A, Heistermann M (2011) Urinary C-peptide of insulin as a non-invasive marker of nutritional status: some practicalities. PLoS One 6:e22398

Hohmann G (2001) Association and social interactions between strangers and residents in bonobos (Pan paniscus). Primates 42:91-99

Hohmann G, Fruth B (2000) Use and function of genital contacts among female bonobos. Anim Behav 60:107-120

Hohmann G, Robbins MM, Boesch C (2006) Frugivory and gregariousness of Salonga bonobos and Gashaka chimpanzees: the influence of abundance and nutritional quality of fruit. In: Hohmann G, 
Robbins MM, Boesch C (eds) Feeding ecology in apes and other primates. Cambridge University Press, Cambridge, pp 123-159

Idani G (1990) Relations between unit-groups of bonobos at Wamba, Zaire: encounters and temporary fusions. Afr Study Monogr 11: 153-186

Inogwabini B-I, Matungila B (2009) Bonobo food items, food availability and bonobo distribution in the Lake Tumba swampy forests, Democratic Republic of Congo. Open Conserv Biol J 3:14-23

Isbell LA, Vuren DV (1996) Differential costs of locational and social dispersal and their consequences for female group-living primates. Behaviour 133:1-36

Ishizuka S, Kawamoto Y, Sakamaki T, Tokuyama N, Toda K, Okamura H, Furuichi T (2018) Paternity and kin structure among neighbouring groups in wild bonobos at Wamba. R Soc Open Sci 5:171006

Ishizuka S, Takemoto H, Sakamaki T, Tokuyama N, Toda K, Hashimoto C, Furuichi T (2020) Comparisons of between-group differentiation in male kinship between bonobos and chimpanzees. Sci Rep 10:251

Jaeggi A, Boose K, White F, Gurven M (2016) Obstacles and catalysts of cooperation in humans, bonobos, and chimpanzees: behavioural reaction norms can help explain variation in sex roles, inequality, war and peace. Behaviour 153:1015-1051

Janmaat KRL, Chancellor RL (2010) Exploring new areas: how important is long-term spatial memory for mangabey (Lophocebus albigena johnstonii) foraging efficiency? Int J Primatol 31:863-886

Janmaat KRL, Olupot W, Chancellor RL, Arlet ME, Waser PM (2009) Long-term site fidelity and individual home range shifts in Lophocebus albigena. Int J Primatol 30:443-466

Johnson CA (2004) The effect of patch size and competitor number on aggression among foraging house sparrows. Behav Ecol 15:412418

Jordan NR, Buse C, Wilson AM, Golabek KA, Apps PJ, Lowe JC, Van der Weyde LK, McNutt JW (2017) Dynamics of direct inter-pack encounters in endangered African wild dogs. Behav Ecol Sociobiol $71: 115$

Kelly RC (2005) The evolution of lethal intergroup violence. P Natl Acad Sci USA 102:15294-15298

Kim J-W, Brown GE, Grant JWA (2004) Interactions between patch size and predation risk affect competitive aggression and size variation in juvenile convict cichlids. Anim Behav 68:1181-1187

Kitchen DM, Cheney DL, Seyfarth RM (2004) Factors mediating intergroup encounters in savannah baboons (Papio cynocephalus ursinus). Behaviour 141:197-218

Koch F, Signer J, Kappeler PM, Fichtel C (2016) The role of the residence-effect on the outcome of intergroup encounters in Verreaux's sifakas. Sci Rep 6:28457

Koenig A (2002) Competition for resources and its behavioral consequences among female primates. Int J Primatol 23:759-783

Launhardt K, Borries C, Hardt C, Epplen JT, Winkler P (2001) Paternity analysis of alternative male reproductive routes among the langurs (Semnopithecus entellus) of Ramnagar. Anim Behav 61:53-64

Lawler RR (2007) Fitness and extra-group reproduction in male Verreaux's sifaka: an analysis of reproductive success from 1989 1999. Am J Phys Anthropol 132:267-277

Lehmann J, Korstjens AH, Dunbar RIM (2007) Group size, grooming and social cohesion in primates. Anim Behav 74:1617-1629

Leighton M, Leighton DR (1982) The relationship of size of feeding aggregate to size of food patch: howler monkeys (Alouatta palliata) feeding in trichilia cipo fruit trees on Barro Colorado Island. Biotropica 14:81-90

Löhrich T, Behringer V, Wittig RM, Deschner T, Leendertz FH (2018) The use of neopterin as a noninvasive marker in monitoring diseases in wild chimpanzees. EcoHealth 15:792-803

Lucchesi S, Cheng L, Janmaat KRL, Mundry R, Pisor A, Surbeck M (2020) Beyond the group: how food, mates, and group size influence intergroup encounters in wild bonobos. Behav Ecol 31:519-532
Magnusson A, Skaug H, Nielsen A et al. (2020) Package "glmmTMB.” R Package version 1021. https://github.com/glmmTMB/glmmTMB. Accessed 26 Aug 2020

Maher CR, Lott DF (2000) A review of ecological determinants of territoriality within vertebrate species. Am Midl Nat 143:1-29

Markham AC, Alberts SC, Altmann J (2012) Intergroup conflict: ecological predictors of winning and consequences of defeat in a wild primate population. Anim Behav 84:399-403

Markham AC, Gesquiere LR, Alberts SC, Altmann J (2015) Optimal group size in a highly social mammal. P Natl Acad Sci USA 112: 14882-14887

Matsuda I, Tuuga A, Higashi S (2010) Effects of water level on sleepingsite selection and inter-group association in proboscis monkeys: why do they sleep alone inland on flooded days? Ecol Res 25: $475-482$

Mech LD, Harper EK (2002) Differential use of a wolf, Canis lupus, pack territory edge and core. Can Field-Nat 116:315-316

Miller RC (2004) Comparison of specific gravity and creatinine for normalizing urinary reproductive hormone concentrations. Clin Chem 50:924-932

Mosser A, Packer C (2009) Group territoriality and the benefits of sociality in the African lion, Panthera leo. Anim Behav 78:359-370

Mulavwa M, Furuichi T, Yangozene K, Yamba-Yamba M, Motema-Salo B, Idani GI, Ihobe H, Hashimoto C, Tashiro Y, Mwanza N (2008) Seasonal changes in fruit production and party size of bonobos at Wamba. In: Furuichi T, Thompson J (eds) The bonobos. Springer New York, New York, pp 121-134

Muruthi P, Altmann J, Altmann S (1991) Resource base, parity, and reproductive condition affect females' feeding time and nutrient intake within and between groups of a baboon population. Oecologia 87:467-472

Noser R, Byrne RW (2007) Mental maps in chacma baboons (Papio ursinus): using inter-group encounters as a natural experiment. Anim Cogn 10:331-340

Nurmi NO, Hohmann G, Goldstone LG, Deschner T, Schülke O (2018) The "tolerant chimpanzee"- towards the costs and benefits of sociality in female bonobos. Behav Ecol 29:1325-1339

Palagi E, Paoli T, Tarli SB (2004) Reconciliation and consolation in captive bonobos (Pan paniscus). Am J Primatol 62:15-30

Parker M (2010) Territoriality and scent marking behavior of African wild dogs in Northern Botswana. $\mathrm{PhD}$ thesis, University of Montana

Pearson SM (1989) Food patches and foraging group size in granivorous birds. Anim Behav 38:665-674

Pisor A, Surbeck M (2019) The evolution of intergroup tolerance in nonhuman primates and humans. Evol Anthropol 28:210-223

Pontzer H, Wrangham RW (2004) Climbing and the daily energy cost of locomotion in wild chimpanzees: implications for hominoid locomotor evolution. J Hum Evol 46:315-333

Pruetz JD, Isbell LA (2000) Correlations of food distribution and patch size with agonistic interactions in female vervets (Chlorocebus aethiops) and patas monkeys (Erythrocebus patas) living in simple habitats. Behav Ecol Sociobiol 49:38-47

Ratcliffe JM, Hofstede HM (2005) Roosts as information centres: social learning of food preferences in bats. Biol Lett 1:72-74

Robinson E, Barker J (2017) Inter-group cooperation in humans and other animals. Biol Lett 13:20160793

Rubenstein D, Hack M (2004) Natural and sexual selection and the evolution of multi-level societies: insights from zebras with comparisons to primates. In: Kappeler PM, van Schaik CP (eds) Sexual selection in primates: new and comparative perspectives. Cambridge University Press, Cambridge, pp 266-279

Ruiter JRD (1986) The influence of group size on predator scanning and foraging behaviour of wedgecapped capuchin monkeys (Cebus Olivaceus). Behaviour 98:240-258 
R Core Team (2018) R: a language and environment for statistical computing. Vienna (Austria): R foundation for statistical computing. Available from: http://www.R-project.org

Saito C (1996) Dominance and feeding success in female Japanese macaques, Macaca fuscata: effects of food patch size and inter-patch distance. Anim Behav 51:967-980

Sakamaki T, Behncke I, Laporte M, Mulavwa M, Ryu H, Takemoto H, Tokuyama N, Yamamoto S, Furuichi T (2015) Intergroup transfer of females and social relationships between immigrants and residents in bonobo (Pan paniscus) societies. In: Furuichi T, Yamagiwa J, Aureli F (eds) Dispersing primate females. Springer Japan, Tokyo, pp 127-164

Sakamaki T, Ryu H, Toda K, Tokuyama N, Furuichi T (2018) Increased frequency of intergroup encounters in wild bonobos (Pan paniscus) around the yearly peak in fruit abundance at Wamba. Int J Primatol 39:685-704

Samuni L, Mielke A, Preis A, Crockford C, Wittig RM (2020) Intergroup competition enhances chimpanzee (Pan troglodytes verus) in-group cohesion. Int J Primatol 41:342-362

Sanchez-Tojar A, Schroeder J, Farine D (2018) Supplementary material for "A practical guide for inferring reliable dominance hierarchies and estimating their uncertainty." J Anim Eco 87:594-608

Schielzeth H (2010) Simple means to improve the interpretability of regression coefficients: interpretation of regression coefficients. Methods Ecol Evol 1:103-113

Schielzeth H, Forstmeier W (2009) Conclusions beyond support: overconfident estimates in mixed models. Behav Ecol 20:416-420

Seiler N, Boesch C, Stephens C, Ortmann S, Mundry R, Robbins MM (2018) Social and ecological correlates of space use patterns in Bwindi mountain gorillas. Am J Primatol 80:e22754

Serckx A, Kühl HS, Beudels-Jamar RC, Poncin P, Bastin JF, Huynen MC (2015) Feeding ecology of bonobos living in forest-savannah mosaics: diet seasonal variation and importance of fallback foods. Am J Primatol 77:948-962

Sherry DS, Ellison PT (2007) Potential applications of urinary C-peptide of insulin for comparative energetics research. Am J Phys Anthropol 133:771-778

Smith JE, Kolowski JM, Graham KE, Dawes SE, Holekamp KE (2008) Social and ecological determinants of fission-fusion dynamics in the spotted hyaena. Anim Behav 76:619-636

Snyder-Mackler N, Beehner JC, Bergman TJ (2012) Defining higher levels in the multilevel societies of geladas (Theropithecus gelada). Int J Primatol 33:1054-1068

Sonerud GA, Smedshaug CA, Bråthen Ø (2001) Ignorant hooded crows follow knowledgeable roost-mates to food: support for the information centre hypothesis. Proc R Soc Lond B 268:827-831

Spellacy WN, Goetz FC, Greenberg BZ, Ells J (1965) Plasma insulin in normal midpregnancy. Am J Obstet Gynecol 92:11-15

Strier KB (1989) Effects of patch size on feeding associations in muriquis (Brachyteles arachnoides). Folia Primatol 52:70-77

Surbeck M, Hohmann G (2013) Intersexual dominance relationships and the influence of leverage on the outcome of conflicts in wild bonobos (Pan paniscus). Behav Ecol Sociobiol 67:1767-1780

Surbeck M, Deschner T, Behringer V, Hohmann G (2015) Urinary Cpeptide levels in male bonobos (Pan paniscus) are related to party size and rank but not to mate competition. Horm Behav 71:22-30
Surbeck M, Coxe S, Lokasola A (2017) Lonoa: the establishment of a permanent field site for behavioural research on bonobos in the Kokolopori Bonobo Reserve. Pan Afr News 24:13-15

Tanner CJ (2006) Numerical assessment affects aggression and competitive ability: a team-fighting strategy for the ant Formica xerophila. Proc R Soc Lond B 273:2737-2742

Taylor CR, Heglund NC (1982) Energetics and mechanics of terrestrial locomotion. Annu Rev Physiol 44:97-107

Thompson E, Knott C (2008) Urinary c-peptide of insulin as a noninvasive marker of energy balance in wild orangutans. Horm Behav 53:526-535

Thompson E, Muller MN, Wrangham RW (2012) The energetics of lactation and the return to fecundity in wild chimpanzees. Behav Ecol 23:1234-1241

Thompson FJ, Marshall HH, Vitikainen EIK, Cant MA (2017) Causes and consequences of intergroup conflict in cooperative banded mongooses. Anim Behav 126:31-40

Toda K, Tokuyama N, Ishizuka S, Furuichi T (2018) A short-term visit of an adult male bonobo from the neighboring unit-group at Wamba. Pan Afr News 25:22-24

Tokuyama N, Sakamaki T, Furuichi T (2019) Inter-group aggressive interaction patterns indicate male mate defense and female cooperation across bonobo groups at Wamba, Democratic Republic of the Congo. Am J Phys Anthropol 170:535-550

Utami SS, Wich SA, Sterck EHM (1997) Food competition between wild orangutans in large fig trees. Int J Primatol 18(6):909-927

Vervaecke H, de Vries H, van Elsacker L (2000) Dominance and its behavioral measures in a captive group of bonobos (Pan paniscus). Int J Primatol 21(1):47-68

Wessling EG, Kühl HS, Mundry R, Deschner T, Pruetz JD (2018) The costs of living at the edge: seasonal stress in wild savanna-dwelling chimpanzees. J Hum Evol 121:1-11

White F (1998) Seasonality and socioecology: the importance of variation in fruit abundance to bonobo sociality. Int J Primatol 19:1013-1027

Whitehead H, Antunes R, Gero S, Wong SN, Engelhaupt D, Rendell L (2012) Multilevel societies of female sperm whales (Physeter macrocephalus) in the Atlantic and Pacific: why are they so different? Int J Primatol 33:1142-1164

Wittemyer G, Douglas-Hamilton I, Getz WM (2005) The socioecology of elephants: analysis of the processes creating multitiered social structures. Anim Behav 69:1357-1371

Worton BJ (1989) Kernel methods for estimating the utilization distribution in home-range studies. Ecology 70:164-168

Wrangham R, Lundy R, Crofoot M, Gilby I (2007) Use of overlap zones among group-living primates: a test of the risk hypothesis. Behaviour 144:1599-1619

Yapuncich GS, Bowie A, Belais R, Churchill SE, Walker CS (2020) Predicting body mass of bonobos (Pan paniscus) with humanbased morphometric equations. Am J Primatol 82:e23088

Yiu S-W, Keith M, Karczmarski L, Parrini F (2015) Early post-release movement of reintroduced lions (Panthera leo) in Dinokeng Game Reserve, Gauteng, South Africa. Eur J Wildl Res 61:861-870

Publisher's note Springer Nature remains neutral with regard to jurisdictional claims in published maps and institutional affiliations. 